\title{
O GOVERNO BIOPOLÍTICO DO MIGRANTE DE SOBREVIVÊNCIA: UMA LEITURA CRÍTICA DA LÓGICA DO CAPITAL HUMANO NA ERA NEOLIBERAL ${ }^{1}$
}

\author{
Cesar Candiotto ${ }^{2}$
}

Resumo: Neste artigo, retoma-se o significado do verbo "governar" como sendo a disposiçấo correta dos homens mediante sua relação com as coisas. Essa definiçâao foi proposta por Michel Foucault, em Segurança, território, população, a partir de sua leitura do pensador renascentista Guillaume La Perrière. Desdobra-se essa designação deixada por Foucault, para analisar a maneira de governar da biopolítica neoliberal contemporânea dos chamados migrantes de sobrevivência, conforme a denominação de Alexander Betts. Na governamentalidade biopolítica neoliberal, a regulação da circulação dos migrantes de sobrevivência é realizada pela sua dependência da circulação das coisas, no caso, o livre fluxo transnacional do capital econômico. Cogita-se que o critério normativo para diferenciar entre a boa e a má circulação dos migrantes, na época contemporânea, não ocorre no terreno da política, mas na esfera neoliberal da biopolítica, especialmente pelos seus desdobramentos no conceito de capital humano. Dele se depreende que náo somente o trabalho produtivo, mas também a vida completa dos indivíduos é avaliada em termos de investimentos e riscos pela aquisição de competências, desenvolvimento de performances e mobilidade contínua. Em Nascimento da biopolítica, de 1979, Foucault considera que a migração é um dos investimentos mais arriscados na aquisição de capital humano, porém, ele a situa de maneira homogênea, como se qualquer migrante pudesse se subjetivar como um empresário e investidor de si mesmo. Sustenta-se que a objetivação negativa dos migrantes de sobrevivência, como improdutivos e indesejáveis, tem como possível causa sua identificação

${ }^{1} \mathrm{O}$ presente artigo foi elaborado com apoio do Conselho Nacional de Desenvolvimento Científico e Tecnológico (CNPq), Chamada Universal 28/2018, Processo: 422565/2018-0, intitulado: "As novas fronteiras da biopolítica contemporânea"; e como resultado parcial da Bolsa de Produtividade em Pesquisa, do CNPq (2018-2021), Processo: 307257/2018-5, intitulado: "Migrantes pobres e indivíduos improdutivos: novas formas de governo da vida e gestấo dos ilegalismos na biopolítica contemporânea" (2019-2022), ambos executados na Pontifícia Universidade Católica do Paraná (PUCPR).

2 Pontifícia Universidade Católica do Paraná (PUCPR), Curitiba, PR - Brasil. (D) https://orcid. org/0000-0002-7172-4618. E-mail: ccandiotto@gmail.com.

https://doi.org/10.1590/0101-3173.2021.v44n2.07.p87

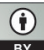

This is an open-access article distributed under the terms of the Creative Commons Attribution License. 
indiferenciada a qualquer outro migrante econômico que busca qualificar seu capital humano. Ao se apresentar esse argumento, evidencia-se o mecanismo de economização da vida que permeia a subjetivaçáo neoliberal e os reducionismos dele resultantes, tal como a redução da vida ao conceito de homo oeconomicus e sua designação como capital humano. Propóe-se que uma maneira de evitar esses reducionismos consiste na tentativa de conversão do olhar em relação ao migrante de sobrevivência, a começar pelo desnudamento da racionalidade que alimenta a produção biopolítica de sua existência.

Palavras-chave: Biopolítica. Governamentalidade. Migração de sobrevivência. Capital humano. Neoliberalismo.

\section{INTRODUÇÃo}

Um dos aspectos característicos do mundo contemporâneo é a intensificação da circulação de populaçôes e dos fluxos de capital. Do ponto de vista político, ela coincide com a queda do Muro de Berlim e a suposta vitória do capitalismo sobre o comunismo, da democracia liberal sobre o socialismo. Da perspectiva econômica, ela é concomitante à ascensão da globalização e do livre mercado, em detrimento da nacionalização da economia. Mesmo antes dos anos noventa do século passado, os processos de produçáo do capital mudaram significativamente, passando de um modelo fordista, seriado e rígido, cuja referência é a fábrica, para um modelo taylorista da economia flexível, cujo ícone são os bancos e bolsas de valores. Desde então, depara-se com a customização dos bens, o crescimento do setor de serviços, a flexibilidade das relaçôes de trabalho e a preponderância do capital financeiro sobre o capital industrial.

A circulação dos fluxos de capital e sua desnacionalização podem ser constatadas pelo deslocamento de grandes indústrias dos países ricos para os países pobres, em busca de máo de obra barata, isenção de impostos e flexibilidade legal em relação aos controles antipoluentes. Dessa forma, as peças que compóem o mesmo produto podem ser fabricadas em diferentes países, sem que sejam montadas em nenhum deles. Essa circulação, inerente à globalização, é concomitante, na esfera do conhecimento tecnológico, ao surgimento da rede global de comunicaçóes - a Internet -, com sua velocidade inaudita de circulação de dados e informaçóes em tempo real. A informação rápida e o acesso ao conhecimento nas novas empresas desterritorializadas de tecnologia, como as do Vale do Silício, acumulam um capital financeiro desproporcional em relação ao espaço físico que ocupam e à mão de obra que empregam, se comparadas a uma indústria de meados do século XX. 
No entanto, essa velocidade da circulação e acúmulo de capital é indissociável do estabelecimento de novas fronteiras de circulação entre as pessoas, muitas delas rígidas e institucionalizadas. Se, por um lado, a circulação do capital é alheia aos regimes políticos, comunista ou capitalista, por outro, o movimento de pessoas está cada vez mais sujeito a dispositivos de segurança, especialmente pela ameaça do terrorismo, do tráfico de pessoas e armas e do crescimento das migraçôes dos países pobres em direção dos países ricos.

A formação de comunidades transnacionais pela livre circulação de serviços, bens e pessoas, como no caso da criação, em 1985, do Tratado Schengen e sua ampliação posterior a vários países da Europa, corresponde à criação de "zonas" que deixam de identificar-se com as fronteiras nacionais da soberania política, tornando-se áreas de segurança máxima gerenciadas por empresas privadas. Em consequência, se a livre circulação de pessoas e coisas é ampliada no interior dessas "zonas", os dispositivos securitários são cada vez mais rígidos para aqueles que pretendem nelas ingressar e residir.

A tentativa de ampliação da circulaçáo de bens, serviços e pessoas coincide com a proposta de criação da ALCA - Área de Livre Comércio das Américas - pelos Estados Unidos, um bloco econômico que seria composto por 34 países, menos Cuba. A primeira reunião é realizada em Santiago do Chile, em 1998, sendo que o início das atividades estava previsto para 2005. Contudo, as negociaçóes falharam, pois, se, de um lado, o futuro bloco propunha a eliminação paulatina das tarifas alfandegárias, de maneira a facilitar a livre circulação de mercadorias, capitais e serviços, por outro, o governo dos Estados Unidos não aceitou a livre circulação de pessoas e trabalhadores dos países integrantes em seu território, especialmente dos latino-americanos.

Como entender essa relação paradoxal entre a circulação das coisas e o fluxo de populaçóes que buscam sobrevivência? Quais são as descontinuidades que mobilizam o acontecimento contemporâneo das migraçóes e a objetivaçáo dos migrantes pela sua captura e apreensão biopolítica? As análises de Foucault, na segunda metade da década de 1970, em torno da governamentalidade, da biopolítica, do neoliberalismo e do capital humano são mobilizadas neste artigo, tanto em suas possibilidades como também em seus limites, a fim da averiguar se realmente se trata de um paradoxo ou, antes, se consiste na própria dinâmica inerente à racionalidade de governo do neoliberalismo contemporâneo. 


\section{Foucault E O SENTIDo Material do governo}

No curso de 1978, no Collège de France, Segurança, território, população, Foucault circunscreve os diversos sentidos do neologismo gouvernementalité. Dentre eles, destacam-se dois: o sentido moral, centralizado nos processos de subjetivação, envolve tanto a condução da conduta de um grupo quanto a condução da conduta individual. Já seu sentido material, em uma ampla aproximação semântica, refere-se ao "[...] deslocamento no espaço, ao movimento que se refere à subsistência material, à alimentação" de uma determinada população (FOUCAULT, 2004a, p. 126).

O sentido moral da governamentalidade é objeto de desdobramentos significativos, nos anos 80 , em suas análises das técnicas de si no cristianismo monástico e nas filosofias grega e romana. Quanto ao seu sentido material, é mencionado discretamente no curso de 1978, mas jamais desenvolvido. Essa ausência é compreensível, porque as grandes ondas migratórias em direção à Europa e, mais tarde, à União Europeia, ainda não constituíam um acontecimento problemático, algo que merecesse, talvez, ser transformado em um objeto de análise conceitual. Os trabalhos mais expressivos a esse respeito surgem somente nos anos 1990 e no começo do século XXI, coincidentes com o advento da globalização econômica e das relaçôes, quase sempre conflitivas, entre os migrantes que buscam socorro na União Europeia e nos Estados Unidos. ${ }^{3}$ A outra razão da ausência de uma análise pontual sobre as populaçóes migrantes concerne aos deslocamentos das pesquisas de Foucault, as quais, nos anos oitenta, oscilam entre o projeto, iniciado em 1976 e várias vezes redimensionado, da História da sexualidade, e os estudos sobre as técnicas de governo de si mesmo e dos outros. Dessa feita, as análises sobre biopolítica, população e neoliberalismo praticamente desaparecem nas suas genealogias dos anos 1980.

Defendo que as pistas de trabalho deixadas sobre o sentido material da governamentalidade, em 1978, embora pouco trabalhadas por Foucault, podem

\footnotetext{
${ }^{3}$ A esse respeito, pode-se mencionar o livro de Étienne Balibar. Nous, citoyens d'Europe? Les frontières, l'État, le peuple (BALIBAR, 2001). Além de permanecer somente no contexto do mundo europeu, Balibar considera que a perspectiva da racialização étnico-social, tal como a diferença entre cidadáo e sujeito, tem, cada vez mais, esgarçado a noção de povo. Diante da cidadania na Europa que surge com a formação da Uniáo Europeia, temos, de um lado, um cidadáo sem um Estado específico; e, de outro, o migrante, um sujeito condenado ao não-direito absoluto. Em decorrência, surge a pergunta de Balibar (2001, p. 240): “[...] quem é o povo na Europa, quer dizer como a soberania popular aí é pensada e organizada, desde o momento em que a Europa almeja ser o espaço e o exemplo de uma política 'democrática?"
} 
ser acionadas para a problematização das populaçóes que migram em busca de sobrevivência, nas últimas décadas. Seguindo a designação de Alexander Betts, nomeio essa população de "migrantes de sobrevivência". ${ }^{4}$ Esse conceito, além de ir ao encontro do vértice material e biopolítico da governamentalidade, contempla a maior parte dos migrantes involuntários, refugiados ou não. Nem todo migrante de sobrevivência é um refugiado, embora o refugiado tenha sido tornado frequentemente um migrante de sobrevivência. Essa designação contrapóe-se à diferença ambígua e homogeneizante entre migrante político no caso, o refugiado - e migrante econômico - todos os que migram por razóes econômicas, desde os que procuram aumentar seu capital, até os que fogem da fome extrema. É temerário situar os migrantes de sobrevivência como simples migrantes econômicos, pois essa inclusão envolve admitir a indistinçáo entre as migraçóes involuntárias em busca de alimento e as voluntárias, as quais almejam qualquer lucro econômico.

Assim, a definiçãao de migrante econômico apresenta-se adequada para alguém que livremente troca seu país de residência por outro, em busca de melhores condiçôes de vida e dispóe de meios suficientes de retornar a seu país quando desejar. Já por migrante de sobrevivência - e ampliando a definição de Betts - compreendem-se todos os que lutam e arriscam tudo pelo direito a fugir da miserabilidade e perseguição na qual se encontram e dependem totalmente do país no qual buscam socorro e acolhida, como garantia do direito a viver.

Sustento que esses migrantes têm sido objetivados em termos biopolíticos, como parte de uma população marcada pela ideia de má circulação em razão de sua relação com os critérios de gestâo do fluxo do capital. Não procuro saber por que a fabricação biopolítica do sujeito migrante se afasta da condição política do cidadáo. Antes, questiono-me por que o estatuto político da cidadania é esgarçado pela constituição biopolítica de outras populaçôes, como a dos migrantes de sobrevivência.

Nas principais análises de 1976, Foucault indica que a população emerge como um objeto conceitual moderno especificado pela sua determinação biológica, seja como efeito do nascimento do dispositivo da sexualidade (como no último capítulo do livro A Vontade de Saber, volume I da História da sexualidade), seja pela emergência do racismo estatal (como na última aula do

\footnotetext{
${ }^{4}$ Alexander Betts (2010, p. 366) denomina os deslocamentos involuntários migraçôes de sobrevivência (Survival Migrations). Esse tipo de deslocamento está inserido nas migraçôes internacionais, embora nem todas as migraçōes internacionais sejam de sobrevivência.
} 
curso Em Defesa da sociedade). Dois anos depois, no curso Segurança, território, população, a populaçáo é problematizada como objeto de governo encarregado de gerir e regular seu deslocamento e comportamento coletivo em um meio qualquer.

Em 1976, as técnicas reguladoras de poder (que ainda não eram chamadas de dispositivos de segurança) estão frequentemente relacionadas à forma do saber da biologia do século XIX, especialmente em sua versão darwiniana. A emergência da biopolítica, e da população como seu objetivo privilegiado, tem como referência o limiar da modernidade biológica. Em 1978, os dispositivos de segurança, considerados a principal técnica de poder governamental moderna, estão envolvidos com os diferentes saberes sobre o movimento e a gestão das populaçóes, como a demografia, a estatística e, principalmente, a economia política.

$\mathrm{Na}$ sequência, busco diagnosticar a regulação da população dos migrantes de sobrevivência e entender o paradoxo em torno de sua circulação, pela perspectiva governamental da biopolítica, o que exigirá o exame da relação entre dispositivos de segurança e economia política. Ao investigar esse paradoxo, proponho desestabilizar a racionalizaçáo política e os excessos de poder que o constituem e o alimentam.

\section{A bOA E A MÁ CIRCULAÇÃo}

Foucault estuda a circulação da produção, no âmbito da economia política moderna, em 1966, no livro As Palavras e Coisas. 5 Do ponto de vista arqueológico, a descontinuidade da relação entre as palavras e as coisas entre dois espaços de saber ou epistemes envolve o desaparecimento de certos objetos a serem conhecidos e o nascimento de outros. Cada episteme, cada espaço arqueológico tem uma gramática correspondente, de modo que um objeto, apreensível na disposição de um espaço de saber, deixa de sê-lo em outro. Assim ocorre com as palavras, as quais, a depender do espaço de saber em que se encontram, são reconfiguradas, quando ocupam outras funçóes, deixando de ter a mesma designação.

Dessa maneira, na Idade Clássica e no domínio das coisas que têm valor econômico, seu a priori histórico é a Análise das Riquezas, e a rede

\footnotetext{
5 Veja-se especialmente a análise sobre a Economia Política, de David Ricardo, no Capítulo VIII, "Travail, vie, langage", em Les mots et les choses (1966, p. 265-275).
} 
de relaçốes que as tornam compreensíveis é a episteme da Representação. A Representação regula o valor de cada mercadoria, bem como determina com certa justiça a ação econômica, concentrada na troca entre as coisas. No entanto, na Modernidade, a relação entre as coisas deixa de ser a mesma. Em vez da importância das trocas e da Representação que determinam seu valor, surgem o trabalho, a produção e sua circulação, no âmbito do a priori histórico da Economia política e sua relação com a episteme da História. Do ponto de vista da arqueologia do saber, é a centralidade do trabalho produtivo e seu envolvimento com aquele que trabalha que permitem o nascimento do homem moderno como homo oeconomicus, ou seja, o homem do trabalho e da produção. E é a Economia política o saber que possibilita a esse homem ver-se como ser finito, marcado pelo sofrimento do trabalho e pela escassez das coisas. Dessa forma, ele precisa sempre produzir mais, em sua luta contra essa escassez, na tentativa de superação de sua condição finita.

Em uma das definiçôes modernas da governamentalidade do curso de 1978, Segurança, território, populaçâo, é retomada a centralidade do saber da Economia política moderna, a qual é situada pelo seu envolvimento com a técnica de poder mais enfatizada desde a segunda metade do século XVIII, que são os dispositivos de segurança. Logo, a governamentalidade designa um poder constituído por táticas e cálculos que envolvem diferentes instituiçóes, procedimentos e análises, das quais a população é produzida como o alvo mais evidente, a economia política é a forma de saber privilegiada e as tecnologias de segurança apresentam-se como o principal dispositivo de poder. Vê-se que, no interior da governamentalidade, o saber da economia política deixa de ser o correlato do nascimento do homem moderno como seu objeto, correspondendo doravante à emergência da população.

Se, em 1966, o conceito de Economia política é estudado arqueologicamente e se, em 1976, a emergência da população no limiar da Modernidade é indissociável do nascimento da biopolítica, já em 1978, a emergência da população é focalizada pela perspectiva genealógica da descontinuidade das artes de governar, no domínio da política. No modelo clássico da política, identificado por Foucault em O Príncipe, de Maquiavel, a primeira preocupação do governante é a manutenção da segurança do território e, por meio dela, a finalidade da conservaçáo do poder soberano e a manutenção da paz social. Focado na administração territorial, o poder soberano inibe que a populaçáo seja evidenciada como preocupação principal do governante. 
Em contrapartida, na literatura anti-Maquiavel, da qual um dos representantes é Guillaume La Perrière, o poder soberano e sua indexação à lei, no século XVI, é deslocado em direção a um novo dispositivo de poder que se impóe na Modernidade, marcado por uma forma específica de governar. Para fins deste artigo, interessa-me somente constatar que, no livro Le miroir politique, o governo é definido por La Perrière como a "[...] disposição correta das coisas, das quais cuidamos para levá-las ao fim conveniente." (FOUCAULT, 2004a, p. 99).

Por "disposição", Foucault entende a distribuição ou deslocamento das coisas em um meio, e de maneira adequada. Por "coisas", ele compreende a complexidade da relação dos "homens com as coisas". O governo está preocupado com a condução dos homens em suas relaçóes com as riquezas, com os recursos e meios de subsistência, mas também com os costumes, hábitos, modos de fazer e pensar. Os objetos do governo são homens em suas relaçóes com acidentes e infelicidades, fome, epidemias, morte. Portanto, a economia política moderna é inseparável da criação de um dispositivo de segurança dedicado ao governo dos homens ou de uma população em sua relação com as coisas.

A releitura da fisiocracia do século XVIII efetuada por Foucault enseja colocar o exercício do governo da população na raiz da economia política moderna. Ela pode ajudar a entender o paradoxo, aludido no início de minha exposição, entre a ampliação contemporânea da livre circulação das coisas e os dispositivos de regulação e controle da migração de sobrevivência.

Foucault sublinha que o predomínio de uma política econômica de autorregulação dos preços dos grãos pela sua livre circulação entre os fisiocratas franceses é concomitante à emergência de dispositivos de segurança populacionais extremamente restritivos. Em razão do perigo da fome e dos miasmas que as cidades enfrentam, naquele momento, é estabelecido um rígido controle do movimento de populaçóes oriundas do campo para a cidade, especialmente de mendigos e sem-teto, segundo enfatiza Foucault (2004a, p. 20): "Tratava-se de organizar a circulação, eliminar o que era perigoso, separar entre boa e má circulação, maximizar a boa circulação, reduzir a má circulação."

$\mathrm{Na}$ opinião de Jeanpierre (2015, p. 216), a leitura da fisiocracia elaborada por Foucault não se limita ao governo das circulaçóes das coisas, estendendo-se ao governo da populaçáo “pelas circulaçóes” ou a uma maneira 
econômica de governo dos homens, cuja referência é a circulação das coisas dotadas de valor. Trata-se de um paradoxo que coincide com a emergência histórica do liberalismo econômico e que, ressalvadas suas descontinuidades, persiste na governamentalidade neoliberal.

Em outras palavras, o acontecimento da desigualdade na regulação do fluxo migratório não pode ser analisado sem se levar em conta a relação que, já no século XVIII, é observada na divisão entre boa e a má mobilidade de uma população, para facilitar a livre circulação das coisas.

Sustento que essa relação é reconfigurada nos séculos XX e XXI, mediante a liberalização do fluxo do capital pelo controle de certas populaçôes por parte dos dispositivos de segurança. Uma coisa náo contradiz a outra: o saber que apregoa a liberalização da economia não tem eficácia sem a regulação diferencial da circulaçáo dos migrantes, entre bons e ruins. $\mathrm{O}$ descompasso entre a liberdade de circulaçáo econômica e a liberdade de mobilidade de pessoas, assim como a desigualdade entre a ampla circulação de algumas populaçóes à custa da severa restrição do fluxo de outras, são os efeitos mais notáveis de uma racionalidade governamental biopolítica neoliberal.

Demonstrarei, na sequência, o efeito de subjetivação derivado dessa nova relação entre homens e coisas, entre trabalhadores e capital, no âmbito da governamentalidade neoliberal, e como dela depende a forma como os migrantes de sobrevivência são governados, na atualidade.

\section{A ECONOMIZAÇÁO DA VIDA}

No curso Nascimento da biopolítica, de 1979, a relação entre economia política e dispositivos de segurança é demarcada pelas descontinuidades da relação entre os homens e as coisas. Essa descontinuidade pode ser elaborada pelos deslocamentos teóricos da noção de trabalho produtivo, na modernidade, de pensadores do século XVIII e XIX, como David Ricardo e Karl Marx, a autores contemporâneos da segunda metade do século XX, como Theodore Schultz e Gary Becker. Se, na modernidade, o trabalho é associado à produção e ao homem que produz pela extração da mais-valia, já na época contemporânea ele é evidenciado pela lógica do capital e sua subjetivação correspondente, a do capital humano. Ao fazer esse recorte, almejo mostrar como o governo dos homens, em sua relação com as coisas, ou seja, dos trabalhadores, em sua imbricação com a produção e acúmulo do capital, é indissociável da 
constituição de um sujeito determinado e afeta diretamente a maneira como os migrantes de sobrevivência são regulados e ao mesmo tempo objetivados, enquanto população, pela governamentalidade biopolítica neoliberal.

De sorte a refinar meu recorte, analisarei somente algumas passagens do curso de 1979 sobre o anarcoliberalismo americano, mais conhecido como a Escola de Chicago, especialmente a leitura feita por Foucault do conceito de capital humano, nos trabalhos de Gary Becker. Consoante esse pensador, diferentemente das análises modernas de Ricardo e, mais tarde, de Marx, que enquadraram o trabalho pela sua função abstrata como força de trabalho, ele pode e deve ser entendido pela sua função concreta, a saber, da perspectiva daquilo que se pretende com seu resultado: o investimento em um capital a ser aperfeiçoado continuamente, diante das transformaçóes da dinâmica do fluxo dos bens, no mundo contemporâneo. Quanto aos homens e mulheres trabalhadores, eles e elas devem desenvolver uma mobilidade contínua, a fim de que se adaptem aos novos imperativos da lógica competitiva que compóe, não somente sua vida econômica, mas também o conjunto de sua existência.

No entender de Marx, o homem que despende sua força de trabalho não se reconhece nas coisas que produz, porque se trata de uma força explorada pela mais-valia, que o impede de nelas reconhecer-se, já que essa força produz somente uma parte dessas coisas, jamais tomadas em seu conjunto; porque, ainda, elas não podem ser possuídas por aquele que as produz. Enfim, porque as coisas produzidas são estranhas àquele que as produz. Já consoante Gary Becker, problematizar o trabalho, em sua concepção concreta, envolve delimitá-lo pelas escolhas do trabalhador de seu investimento em capital. Além disso, o trabalhador imagina a si mesmo como um produtor de capital. Se o homo oeconomicus clássico é o homem da troca, se, na modernidade, ele é o sujeito produtivo, na época contemporânea, ele é, conforme Revel (2018, s/p), "[...] ao mesmo tempo sujeito produtivo e sujeito-capital" ou, ainda, produtor porque capital. É a possibilidade de capitalizar-se permanentemente pela mobilidade intermitente como capital humano que faz dele um sujeito produtivo.

Quem "renuncia” à constante mobilidade, em busca da acumulação de seu capital humano e adaptação de suas competências e habilidades às inovaçóes decorrentes da lógica de modificação das variáveis do ambiente competitivo de mercado, é ameaçado pela automarginalização econômica e social. Nessa nova lógica, a oposição entre trabalho e capital é dissolvida, pois a população dos trabalhadores deixa de ser apreendida pelo seu ser explorado e pela sua 
resistência à acumulação de capital. Os trabalhadores são objetivados em função das escolhas e prioridades dos resultados de seu trabalho. Perguntamse permanentemente como investir em si mesmos no trabalho que realizam e, finalmente, subjetivam-se como os principais responsáveis pelas escolhas de investimento, no intuito de se tornarem empreendedores de si mesmos.

Essa delimitação está intimamente relacionada à perspectiva de que o trabalho produtivo, na configuraçáo neoliberal, é uma forma de capital cujas condiçóes de proteção e acumulação não são de responsabilidade do Estado e das instituiçóes, pois delegadas exclusivamente aos indivíduos. A função do Estado limita-se a chamar a atenção para a responsabilidade dos indivíduos e das populaçóes, a respeito da qualidade de suas escolhas. Se na governamentalidade política dos Welfare States, uma das funçôes do Estado é garantir a proteção social (nesse caso, do trabalho), na governamentalidade neoliberal, ele se torna um agente moralizante. Por essa razão, a responsabilidade há que entenderse como responsabilização, ou seja, uma regulação encarregada de desonerar as responsabilidades dos Estados e transferi-las aos próprios indivíduos, doravante os únicos sujeitos de seu êxito ou fracasso. ${ }^{6}$

O trabalho deixa de ser percebido como uma força abstrata cuja extração e alienação é condição para a mais-valia. Ele é igualmente irredutível à mera mercadoria intercambiável, no interior de um sistema de equivalências. Esfuma-se, portanto, na lógica do capital, de modo que sua função se esgota na produção de capital humano, o qual, uma vez adquirido, não pode ser vendido como uma mercadoria qualquer. De acordo com Brown (2016, p. 62), "[...] quando tudo é capital, a força de trabalho desaparece como uma categoria, assim como sua forma coletiva, a classe, e, ao desaparecer, carrega consigo a base analítica para a alienação, exploração [...]"

Conforme já salientado, o capital humano deixa de ser demarcado somente pela perspectiva moderna do indivíduo produtivo deduzido de suas relações de trabalho, conjugando-se, cada vez mais, com a imagem do sujeito investidor de si mesmo, em todos os aspectos da vida. Além de sentir-se produtivo, considerando-se como empresa, é necessário sentir-se um investimento atraente, com um portfólio amplo, o qual envolve preferências de lazer, trabalho voluntário, seletividade de amizades promissoras e escolha

${ }^{6}$ Como sublinha Brown (2016, p. 220, tradução nossa). “[...] a responsabilização, especialmente como política social, é a atribuição de peso moral à entidade que se encontra no final da cadeia. A responsabilização atribui ao trabalhador, ao estudante, ao consumidor ou ao indigente a tarefa de discernir ou adotar as estratégias corretas de autoinvestimento e espírito empreendedor, para prosperar e sobreviver. Nesse sentido, trata-se de uma manifestação da capitalização humana.” 
de parceiros afetivos. O capital humano produtivo, enfatizado por Foucault, em 1979, tem sido reconfigurado, segundo Brown, diante da importância concedida nos últimos decênios ao capital humano financeiro. Nesse caso, "financeiro" não quer dizer monetizável, posto que designa a adesão a uma racionalidade que considera todas as atividades da vida como objetos de investimento, cujo efeito maior é a "economizaçáo" da vida. ${ }^{7}$

Tempo de trabalho e tempo de vida, espaço de trabalho e espaço de ociosidade mantêm entre si uma relação inseparável. Uma normalização assujeitadora brota da lógica da governamentalidade neoliberal: a exigência da constante mobilidade dos indivíduos e populações em direção da melhoria contínua, do aprimoramento e adaptação de suas faculdades cognitivas, físicas e emocionais. Trata-se de saber mais, prevenir-se para manter-se saudável e emocionalmente controlado, a fim de produzir mais. Como se náo bastasse, é necessário procurar ser mais acessado, mais valorizado, mais curtido nas redes sociais e assim por diante. Busca-se a constituição de um sujeito da performance, pelo qual sua verdade e seu ser são aquilatados pelo seu sucesso ou fracasso no contexto de um governo administrativo da vida (DARDOT; LAVAL, 2010, p. 442).

A mobilidade perpétua pela qual indivíduos e populações são objetivados e se subjetivam, segundo a racionalidade do fluxo do capital financeiro, é criadora de um tipo específico de sofrimento decorrente do possível fracasso na definição das escolhas certas, da falta de calibragem para assumir riscos com previsão de resultados seguros, da chance sempre presente de ser esquecido e preterido pelos pares. Depara-se com a emergência de um processo de sujeição inseparável do sentimento de culpa moral, para a qual não se tem mais perdáo nem salvaçáo.

\footnotetext{
${ }^{7}$ A economização da vida engloba, em primeiro lugar, o fato de que somos somente homo oeconomicus em toda a esfera da vida, enquanto economistas clássicos, como Adam Smith e David Ricardo, estabelecem a relaçáo entre vida política e vida econômica, sem reduzir a primeira à segunda. Em seguida, ela caracteriza o homo oeconomicus como uma forma de capital humano para fortalecer seu ser competitivo, e náo tanto para valorizar sua figura de homem do interesse ou da troca, como entre os clássicos. Em terceiro lugar, ela indica que o modelo específico do capital humano é cada vez mais extraído do modelo do capital financeiro e de investimento e năo somente do capital produtivo e empresarial (BROWN, 2016, p. 51-53). Embora W. Brown valorize mais o capital humano financeiro baseado no autoinvestimento, penso que este último náo está ausente na análise de Foucault de 1979, embora ele não se refira ao autoinvestimento da mesma maneira e, até mesmo porque, há aproximadamente quarenta anos, quando a economia do capital flexível e a tecnologia das redes sociais ainda era embrionária, o capital humano produtivo continua a ser relativamente mais valorizado que o capital financeiro. A financeirização da economia é mais evidente a partir da década de 1990, com o advento da globalização e o rápido desenvolvimento das tecnologias da informação.
} 


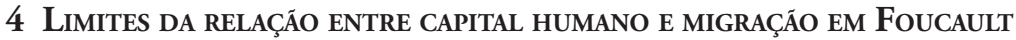

A governamentalidade neoliberal, ao menos na leitura proposta por Foucault a respeito do pensamento de Gary Becker, inaugura uma relação entre homens e coisas, entre circulação de populaçóes e fluxo do capital, segundo a qual a restriçáo da primeira deve estar à serviço da expansão infinita do segundo. Quando indivíduos e populaçóes são estimulados a se subjetivarem como capital humano, há uma dinâmica que remonta à fisiocracia do século XVIII, ainda que não se refira mais aos mesmos objetos de análise. Essa dinâmica considera que não é a produção do fluxo desigual entre as populaçóes que deveria obrigar a mudança do fluxo das coisas e do capital. Pelo contrário. A mobilidade das populaçôes torna-se governada e regulada de modo diferencial, conforme a racionalidade da circulação das coisas, sendo normalizada como uma forma de fluxo e produçáo de capital.

No âmbito dessa racionalidade, as migraçóes de sobrevivência, de países pobres para os países ricos, são objetivadas negativamente. Ao mesmo tempo que a lógica do capital humano valoriza os indivíduos e populaçóes que investem em sua mobilidade, no sentido de não se conformarem ao lugar no qual se encontram (tanto o local em que vivem como também, denotativamente, as funçôes que ocupam, no âmbito das relaçóes de produção e reproduçáo do capital), ela também regula essa mobilidade, separando-a entre a boa e a ruim. A lógica neoliberal do capital humano é biopolítica, porque aprecia os indivíduos que assumem riscos elevados, em seu autoinvestimento, ao mesmo tempo que abandona ao seu próprio destino aqueles que arriscam tudo, inclusive as próprias vidas, em busca de sobrevivência. Em consequência, é valorizado o risco, mas não qualquer risco; incentivada a mobilidade, mas não toda mobilidade.

Em uma única passagem do curso de 1979, Nascimento da biopolítica, Foucault (2004b, p. 236-237) estabelece a relação entre capital humano e migração:

Entre os elementos constituintes do capital humano, também é necessário contar a mobilidade, ou seja, a capacidade de um indivíduo de se deslocar, especialmente a migração. [...] A migração é um investimento, o migrante é um investidor. Ele é um empreendedor de si mesmo que faz um certo número de despesas de investimento para obter uma certa melhoria. A mobilidade de uma população e a capacidade que ela tem de fazer escolhas de mobilidade que são escolhas de investimento para obter uma melhoria nos salários, tudo isso permite reintroduzir esses fenômenos, não como efeitos puros e simples de mecanismos econômicos que desbordariam 
os indivíduos e que, de alguma forma, os vincularia a uma imensa máquina da qual náo seriam senhores; isso permite analisar todos esses comportamentos em termos de empresa individual, de empresa em si mesmo com investimentos e rendas.

A passagem indica que a migraçáo é um dos exemplos mais importantes para a aquisição de capital humano, mas também um dos mais arriscados. $\mathrm{O}$ migrante que se desloca voluntariamente é considerado um empresário de si mesmo, alguém capaz de gerar mais renda, em virtude de sua mobilidade arriscada. Surpreende, contudo, que o autor de Vigiar e punir náo vai além da referência correspondente à objetivação neoliberal da "boa migração", dando a sensação de uma tácita homogeneidade entre as diferentes migraçóes e como essa problemática denota sempre uma produção discursiva e não-discursiva. Por certo, a equação entre "escolha de mobilidade" e "escolha de investimento" é reservada aos migrantes voluntários, os quais agregam alto valor em capital humano ou dinamizam o fluxo de capital, nos países de acolhida.

Mesmo no contexto dos anos setenta do século passado, e em razão mesmo das análises que realizara da circulação de pessoas e coisas, no âmbito da fisiocracria do século XVIII, Foucault poderia ter percebido que a "boa migração" é correlata da produção neoliberal e biopolítica da "migração ruim"; que a acolhida do migrante econômico investidor de si mesmo é completamente assimétrica em relação à recusa frequente daqueles que se deslocam involuntariamente, por causa das guerras civis e da fome; ou ainda das dificuldades enfrentadas por parte daqueles que possuem algum capital humano, mas cujo valor é pouco ou quase nada reconhecido, nos países que os recebem. Dessa feita, a regulaçáo restritiva da "má mobilidade" dos migrantes de sobrevivência é indissociável da dinamização da expansão da "boa circulaçáa" do fluxo do capital, especialmente do homo oeconomicus como capital humano. Depreende-se que a migração mais arriscada não é aquela que objetiva o acúmulo de capital humano, porém, é a que arrisca tudo, inclusive a própria vida física.

De resto, haveria que retomar a afirmação de Foucault, no texto $A$ filosofia analítica da política, de que o grande problema do século XX, pelo menos na Europa, não é tanto o das lutas contra o empobrecimento e a miséria daqueles que justamente produzem a riqueza, contudo, o excesso de poder demonstrado pelo fascismo e nazismo. Foucault não diz que o problema da miséria e as lutas contra a exploração econômica tenham completamente 
desaparecido, mas ressalta que a marca do século XX são as lutas contra o abuso do poder político. Esse excesso, materializado no fascismo e no estalinismo, é uma "dobra" da exploração da produção e distribuição das riquezas do século XIX. Ressalta Foucault (2001, p. 536):

[...] fascismo e estalinismo somente prolongaram uma série de mecanismos que já existiam nas estruturas sociais e políticas do Ocidente. Afinal de contas, a organizaçáo dos grandes partidos, o desenvolvimento dos aparelhos policiais, a existência de campos de repressão como os campos de trabalho, tudo isso é uma herança constituída das sociedades liberais que o estalinismo e o fascismo somente recolheram.

Evidentemente, ele pretende fazer uma crítica da racionalidade política e, nesse sentido, toma distância da análise que apresenta o excesso do poder político como "derivação" da exploração econômica, ao modo da relação entre superestrutura e infraestrutura.

Ora, essas relaçôes são muito mais complexas e circulares. Além disso, se elas deixarem de limitar-se ao contexto exclusivamente europeu e pautadas por preocupaçóes que transcendem o interesse teórico direto de Foucault, só reforçam a complexidade aludida por ele. Talvez tivesse sido interessante que, em suas análises, fosse prestada maior atenção ao fato de que a produção e a distribuição das riquezas na Europa, tanto no século XIX quanto no século XX, são indissociáveis do acontecimento da colonização, especialmente da África. Se o problema da miséria na Europa do século XX deixou de ser tão "urgente", já o excesso e constante abuso do poder político, bem como a produção da miserabilidade e da morte pela exploraçáo econômica e extrativista, decorrente da colonização, têm tornado muitos países e regiôes verdadeiros "estados de urgência" intermináveis.

Se a atitude crítica é legitimamente exercida como tentativa de limitação do excesso do poder político, ela também pode ser pensada como o exercício da circunscrição e minimização do abuso do poder econômico, não somente dos governantes de onde partem os migrantes, mas também daqueles que colonizaram esses países durante séculos e que, de alguma forma, ainda colaboram na produção e manutenção de sua extrema pobreza. Não seria o excesso de poder colonial e neocolonial um dos produtores da exploração econômica e, por extensão, da migração de sobrevivência que atualmente ressoa como um efeito reverso? 
Não deixa de ser igualmente surpreendente que o neoliberalismo, em suas diferentes versóes, jamais seja problematizado por Foucault, em suas externalidades, ou seja, em seus efeitos negativos, diante do efeito esperado do acúmulo do capital. No máximo, ele dá a entender que, na sua versão radical behaviorista, o indivíduo é eminentemente governável, todavia, não sublinha até que ponto seus dispositivos de segurança são também produtores de "pobreza e miséria". Se, de um lado, ele trabalha a pobreza e a miséria, de outro, elas estão sempre associadas à problemática da normalização moral, como em História da loucura, onde é destacada a percepção moralizante do pobre e do miserável, na Idade Clássica, mas sem que ela seja considerada um dos efeitos da desigualdade social produzida pela exploração, concomitante ao advento econômico e político da burguesia. Se, conforme entende G. Le Blanc (2011), os migrantes de sobrevivência podem ser assemelhados aos pobres da Idade Clássica, no entanto, é insuficiente que sua objetivação seja limitada à sua percepção moral.

Assim, ao mesmo tempo que os migrantes de sobrevivência são moralmente concebidos como clandestinos, vagabundos e potencialmente terroristas, eles também são política $e$ economicamente explorados e, por isso, úteis. Tem-se uma utilidade política, pois o estabelecimento de novas fronteiras sociais e antropológicas reforça o retorno arcaico de identidades coletivas nacionalistas voltadas para a reafirmação de uma soberania já erodida, no âmbito das quais os migrantes são produzidos como ameaça permanente ao vivre-ensemble. Trata-se também de uma utilidade econômica, porque ela refina e perpetua os mecanismos de exploração, tornando os corpos dos migrantes economicamente úteis, sempre que náo proporcionem uma baixa dos salários e náo diminuam a lucratividade de um patronado que usufrui do trabalho informal e mal pago.

Em relaçáo aos migrantes de sobrevivência, a racionalidade do capital humano opera ao modo de suavização e adesão subjetiva a essa dupla utilizaçáo política e econômica. Sendo eminentemente uma lógica produtora de desigualdade, ela tenta convencer que toda migração é homogênea, que todos os migrantes são fracassados e perigosos. Essa homogeneização da lógica neoliberal do capital humano é indissociável da divisão que Foucault evidencia, na fisiocracia clássica, entre a boa e a má circulação, mas que não alcança identificá-la na maneira neoliberal de governar.

No entender de Revel (2018), seria uma posição cínica tentar enquadrar os migrantes totalmente desprotegidos que chegam à Europa ou alhures como 
investidores radicais, em sua escolha de mobilidade e investimento, à medida que o risco que correm é muito maior que todos os demais. O grande fluxo da migração de sobrevivência não tem essa possibilidade de escolha, posto que ela é, de antemão, apresentada como ameaça à dinâmica do capital humano. Considera-se que os migrantes de sobrevivência não sabem onde investir, onde morar, com quem se casar, com quem estabelecer amizades, quando migrar ou aperfeiçoar-se. Eles são os responsáveis por sua condição, porque não aderiram, no momento certo, à única alternativa estimulada pela condução da conduta neoliberal, que é a da economização da vida.

Consoante a perspectiva neoliberal, não há razão para acolher esses migrantes, no interior da lógica do autoinvestimento em capital humano. Como os únicos responsáveis por sua situação de pobreza e miserabilidade, eles constituem o exemplo excelso dos indesejáveis do mundo.

\section{ConsideraçóEs FinaIS}

A racialização dos migrantes de sobrevivência, ou seja, sua representação simbólica como inimigo potencial e perigo político e econômico, não pode ser atribuível somente à sua cultura ou etnia, embora tais dimensões sejam dela constitutivas. Essa racialização também pode ser considerada como o efeito da construção real e simbólica da racionalidade do capital humano neoliberal, cuja regulação separa, de um lado, as populaçóes portadoras de capital humano produtivo, criativo e inovador, e, de outro, as que não exteriorizam senão a marca da miserabilidade e necessidade de socorro e acolhida. Destarte, o sempre insaciável aumento qualitativo e quantitativo de capital humano, na sua versão neoliberal, pode ser designado como a reconfiguração do imperativo biopolítico do fazer viver, cujo reverso é o deixar viver-deixar morrer populaçôes consideradas improdutivas, porque irresponsavelmente não souberam ou escolheram investir em si mesmas.

Diante da regulação normativa assentada no fluxo ininterrupto do capital (humano), um dos grandes desafios de nosso tempo consiste em saber como podemos freá-lo, mesmo tendo consciência de que é deveras difícil impedi-lo. Um dos caminhos pode ser o da conversão do olhar consistente em deixar de ver os migrantes de sobrevivência, especialmente das chamadas zonas improdutivas ou campos de detençáo, como populaçóes que ameaçam meu trabalho e minha vida. Criar condiçôes políticas e institucionais para tornar esse outro visível, evidenciando suas demandas de socorro, acolhida, 
pertença e reconhecimento é uma maneira de nuançar os limites da aparente neutralidade da circulação "natural" do capital, a qual, na verdade, tem se revelado uma grande produtora de novas sujeiçôes.

Enfim, não desconsidero que os migrantes de sobrevivência sejam mal acolhidos ou até mesmo barrados nas fronteiras, por conta de seu modo de vida e seus costumes, de sua cor de pele ou de sua história. Procurei antes enfatizar que a objetivação moral negativa que lhes é atualmente impetrada tem como parâmetro uma lógica que os torna os únicos responsáveis por seu fracasso, desobrigando, dessa forma, as comunidades políticas que têm a obrigação de acolhê-los, pois todas elas são Estados-parte comprometidos com a Declaração Universal dos Direitos humanos de 1948, a qual garante o direito a migrar.

A dissimetria entre a circulação das coisas e a mobilidade dos migrantes de sobrevivência, inicialmente paradoxal, apresenta-se perfeitamente compatível com a lógica neoliberal pela qual o aumento do fluxo do capital, o qual absorve não somente o trabalho, mas também se estende à existência completa dos indivíduos, tem como contraponto os dispositivos restritivos de segurança aplicados àqueles que não souberam investir em si mesmos. Seria ininteligível a valorização da boa circulação de pessoas, sem a criação de uma zona de regulação restritiva de sua má circulação. Além disso, seria ingênuo pensar que essa gestáo diferencial da circulação de pessoas se encontra dissociada da circulação das coisas ou do fluxo e acúmulo do capital (humano). Resulta que, se quisermos enfatizar as lutas em torno de uma política migratória, um de seus flancos consiste na dissecação da racionalidade que a sustenta e dos efeitos que ela proporciona.

CANDIOTTO, C. The biopolitics government of survival migrant: a critical reading of the logic of human capital in the neoliberal era. Trans/form/ação, Marília, v. 44, n. 2, p. 87-106, Abr./Jun, 2021.

Abstract: In this article I follow the meaning of the verb "to govern" as the right disposition of men in their relation with things. This definition is proposed by Michel Foucault in Security, territory, population through his reading of the renaissance thinker Guillaume de La Perrière. I unfold and spread this meaning by analyzing the way of government that characterizes contemporary neoliberal biopolitics in its relation with the so called migrants of survival according to the definition of Alexander Betts. 
On the neoliberal biopolitical governmentality, the regulation of survival migrants is structured by its dependence on the circulation of things; in this case, the transnational flow of economic capital. I consider that the normative criterion that distinguishes good and bad circulation of migrants nowadays isn't based on classical political ground. It's made by the neoliberal axis of biopolitics, especially by the unfoldings of human capital concept. From this concept comes the idea that not only the productive work, but also the entire life of individuals is evaluated in terms of investments and risk to the acquisition of competences, on the development of performance and permanent mobility. On The Birth of Biopolitics, in 1979, Foucault considers that migration is one of the riskiest ways to earn human capital. Nevertheless he considers migration in an homogenous way, as if any migrant could subjective himself as a self-entrepreneur. I consider that the negative objectivation of survival migrants as unproductive and undesirables has as its possible cause their undifferentiated identification with any economical immigrant that searches to qualify his human capital. In presenting this argument, I point the mechanisms of economization of life which crosses neoliberal subjectivation and the reductionisms that results from it, as the reduction of life to homo economicus and its designation as human capital. I propose that a manner to avoid those reductionisms consists in the conversion of the look pointed to the survival migrants, starting by showing the rationality which feeds the biopolitical production of their existences.

Keywords: Biopolitics. Gouvernemnt. Survival Migrant. Human Capital. Neoliberalism

\section{REFERÊNCIAS}

BALIBAR, E. Nous, citoyens d'Europe? Les frontières, l'État, le peuple. Paris: La Découverte \& Syros, 2001.

BECKER, G. Crime and punishment: an economic approach. Journal of Political Economic, v. 73, n. 2, 1968, p. 196-217.

BETTS, A. Survival Migration: A New Protection Framework. Global Governance: A Review of Multilateralism and International Organizations, v. 16, n. 3, 2010, p. 361-382.

BROWN, W. El Pueblo sin atributos: la secreta revolución del neoliberalismo. Traducción de Víctor Altamirano. Barcelona: Malpaso, 2016 (Edición E-book).

DARDOT, P.; LAVAL, C. La nouvelle raison du monde: essai sur la société néolibérale. Paris: La Découverte, 2010.

FOUCAULT, M. Les mots et les choses. Paris: Gallimard, 1966.

FOUCAULT, M. La philosophie analytique de la politique. In: Dits et écrits II. 19761988. Paris: Quarto/Gallimard, 2001. v. II, p. 534-551.

FOUCAULT, M. Sécurité, territoire, population. Cours au Collège de France. 19771978. Ed. François Ewald et Alessandro Fontana, par Michel Sennellart. Paris: Gallimard; EHESSE; Seuil, 2004a.

FOUCAULT, M. Naissance de la biopolitique. Cours au Collège de France, 19781979. Édition établie par François Ewald et Alessandro Fontana, par Michel Senellart, Paris: Gallimard; Seuil, 2004 b. 
JEANPIERRE, L. Capitalisme et gouvernement des circulations. In: LAVAL, Ch.; PALTRINIERI, L.; TAYLAN, F. (org.). Marx \& Foucault. Lectures, usages, confrontations. Paris: La Découverte, 2015, p. 213-227.

LE BLANC, G. História da loucura na Idade Clássica: uma história da pobreza. In: MUCHAIL, S. T.; FONSECA, M. A. da; VEIGA-NETO, A. (org.). O mesmo e o outro: 50 anos de História da loucura. Belo Horizonte: Autêntica, 2013, p. 173-189.

REVEL, J. Ne pas faire vivre et laisser mourir. Revue Esprit, juil./août 2018. Disponível em: https://esprit.presse.fr/article/judith-revel/ne-pas-faire-vivre-et-laisser-mourir-41602. Acesso em: 10 fev. 2020.

Recebido: 28/3/2020

Aceito: 09/7/2020 